\title{
Cross Effect of Natural Rubber and Annealing on the Properties of Poly(Lactic Acid)
}

\author{
Sándor Hajba1*, Tamás Tábi1,2 \\ 1 Department of Polymer Engineering, Faculty of Mechanical Engineering, Budapest University of Technology and Economics, \\ H-1111 Budapest, Múegyetem rkp. 3., Hungary \\ 2 MTA-BME Research Group for Composite Science and Technology, H-1111 Budapest Múegyetem rkp. 3., Hungary \\ *Corresponding author, e-mail: hajba@pt.bme.hu
}

Received: 10 July 2018, Accepted: 30 May 2019, Published online: 01 August 2019

\begin{abstract}
In our work, the effect of Natural Rubber was investigated on the properties of Poly(Lactic Acid). We produced blends containing 0-20 wt\% Natural Rubber with different manufacturing technologies (internal mixer and twin screw extrusion) and injection molded specimens from the blends. In addition to the effect of Natural Rubber on PLA, we also examined the effect of D-Lactide content and also the combined effect of Natural Rubber and the crystalline structure developed during heat treatment (annealing) of PLA. A positive synergistic effect was found between the presence of Natural Rubber and the developed crystal structure regarding impact strength and thus high toughness blends could be produced. Finally, it was found that this synergistic effect is even more stronger due to the smaller and better dispersed Natural Rubber particles.
\end{abstract}

\section{Keywords}

poly(lactic acid), biopolymers, annealing, natural rubber, increased toughness

\section{Introduction}

Nowadays cheap and easily processable plastics are widely used in almost all areas of life. The demand for plastics is steadily growing, and the largest amount of plastics is used by the packaging industry. Due to the enormous amount of plastics used, recycling is of paramount importance. As environmental consciousness increases, alternative possibilities, such as renewable resource-based biopolymers come to the forefront instead of depositing plastic waste at landfills or garbage dumps.

These biopolymers can be divided into three groups: agricultural-based plastics, plastics produced by microbes and plastic manufactured by biotechnology. The most important member of the three groups is polylactic acid (PLA), which is the focus of most research and development. It is produced by the polycondensation of lactic acid, which in turn is obtained from the carbohydrates of various cereals by fermentation. It stands out from biopolymers due to its numerous advantageous properties, such as tensile strength $(60 \mathrm{MPa})$, optical transparency, excellent UV resistance and low processing temperature $\left(170-190{ }^{\circ} \mathrm{C}\right)$, and its low price compared to other biopolymers (2 Euro/kg) [1-4]. PLA is a semicrystalline polymer, which can have four crystalline structures based on the conditions of crystallization [3, 5-9]. In practice, during cooling from melt state, the crystalline structure depends on the crystallization temperature: above $120^{\circ} \mathrm{C}$ the more perfect $\alpha$ structure is present, while under $100{ }^{\circ} \mathrm{C}$ the less perfect $\alpha$ ' structure; between $100{ }^{\circ} \mathrm{C}$ and $120^{\circ} \mathrm{C}$ there is a mixture of the two. PLA also has two rarer crystallite types: $\beta$ and $\gamma$. The $\beta$ type forms during stretching at elevated temperatures, for example during the production of PLA fibers, while the $\gamma$ type forms during the epitaxial crystallization of PLA on a hexamethylbenzene substrate [10-12].

PLA, however, has numerous disadvantages as well, which make its use difficult. Such are its high sensitivity to moisture, its aging, its low glass transition temperature $\left(55^{\circ} \mathrm{C}\right)$ but its greatest disadvantage is its rigidity, which is shown by its $2 \mathrm{~kJ} / \mathrm{m}^{2}$ notched and $23 \mathrm{~kJ} / \mathrm{m}^{2}$ unnotched Charpy impact strength [1-4].

A possible method of improving the toughness of PLA is to combine it with natural rubber (NR) [13-22]. Natural rubber (NR) the base material of a natural polymer used in very large amounts. The molecular chains are built up of repeated isoprene units in cis-1,4 bonds. The base material of NR, 
latex, is obtained from the rubber tree (Hevea Brasiliensis). This aqueous dispersion contains $30-40 \%$ cis- 1,4 polyisoprene, and small amounts of fatty acids, carbohydrates and inorganic salts. The natural rubber can be obtained from the dispersion by spray drying or coagulation, then the natural rubber is stabilized by smoking [23, 24].

Natural rubber is not miscible with PLA; it appears in it as a second phase. For natural rubber to increase the toughness of PLA, the following conditions must be fulfilled: the NR particles have to be dispersed in the matrix as finely as possible (i), the particles should be as small as possible (ii), there should be good adhesion between the PLA and the NR (iii). Also, the natural rubber has to be chosen so that it is stable at the manufacturing temperature of the blend (iv) and its glass transition temperature should be about $20{ }^{\circ} \mathrm{C}$ lower than the final temperature of use (v). The only disadvantage of NR is that it can considerably (up to $50 \%$ ) decrease the strength of PLA, depending on its amount. The goal is to find the optimal amount of NR, taking into account the increase in toughness and the decrease in strength.

The effect of combining PLA with NR has been analyzed by several researchers, Bitinis et al. [13] examined mixtures made with an internal mixer and containing $0-20 \mathrm{wt} \% \mathrm{NR}$. They found that increasing the processing temperature or NR content causes an increase in the average particle size, which is, unfavourable, but mixing rpm does not have much effect. NR content above $10 \mathrm{wt} \%$ is not recommended due to the appearance of large particles. They also mentioned the slight positive effect NR has on crystallization, but they did not analyze it in detail, nor did they perform other tests than tensile tests to investigate the effect of NR. Xu et al. [14] had similar results, as did Pongtanayut et al. [15], but they added that adhesion between PLA and NR improved as a result of epoxidation. Jaratrotkamjorn et al. [16] also investigated the effect of the surface treatment of NR by epoxidizing NR and grafting PMMA on NR. The researchers attributed the lack of pronounced improvement to the brittle coupling agents. In some cases, in addition to natural rubber [17] or other toughening additives [18], nucleating agents were also added to PLA in small amounts so that the crystalline fraction of PLA increased.

$\mathrm{Xu}$ et al. [14] and Yuan et al. [20-22] also investigated PLA/NR blends with vulcanized and unvulcanized NR in several of their papers. They found that at $35 \mathrm{wt} \% \mathrm{NR}$ a considerable brittle-tough transition could be observed, when Izod impact strength increased from
$70 \mathrm{~J} / \mathrm{m}$ to $500 \mathrm{~J} / \mathrm{m}$, but tensile strength decreased considerably, which they partly attributed to the inferior adhesion between the PLA and the NR. They managed to achieve an improvement compared to unvulcanized PLA/NR blends with the double continuous structure achieved by curing NR with peroxide in their dynamic vulcanization experiments, where strength decreased less with higher NR contents than without vulcanization.

In this paper we examine the effect of the amount of NR on the properties of PLA, and the relationship between processing conditions, the resulting morphology and mechanical properties. We also investigate the combined effect of the presence of NR and the crystalline structure of PLA, as this is a little researched area.

\section{Materials and methods}

We used three types of PLA with different D-lactide contents: Natureworks (USA) 3052D, 3001D and 3100HP (Table 1). We used as filler the TSR CV 60 natural rubber, which has a Mooney (ML1+4) viscosity of 60, and is distributed by Variachem Kft. (Hungary).

We made PLA blends containing 2, 5, 10, 15, and $20 \mathrm{wt} \%$ NR. We used two mixing technologies to mix the NR into the PLA: an internal mixer (Brabender Plastograph) and twin-screw extrusion (Labtech LTE 26-44). Processing temperature was $190^{\circ} \mathrm{C}$ with both technologies. In the case of internal mixing, rotational speed was $501 / \mathrm{min}$, and mixing time was 5 minutes, while in the case of extrusion, rotational speed was $20 \mathrm{1} / \mathrm{min}$. We made dumbbell-shaped specimens from the blends with an Arburg Allrounder 370S 700-290 injection molding machine. Melt temperature was $190{ }^{\circ} \mathrm{C}$, while mold temperature was $25^{\circ} \mathrm{C}$. Shot volume was $43 \mathrm{~cm}^{3}$, injection speed was $50 \mathrm{~cm}^{3} / \mathrm{s}$ switchover volume was $12 \mathrm{~cm}^{3}$ screw speed was $15 \mathrm{~m} / \mathrm{min}$ holding

Table 1 The main properties of the pol(lactic acid)s used

\begin{tabular}{lccc}
\hline Properties/PLA type & $3100 \mathrm{HP}$ & $3001 \mathrm{D}$ & $3052 \mathrm{D}$ \\
\hline D-lactide content [\%] & 0.5 & 1.4 & 4 \\
Tensile strength [MPa] & 65 & 63 & 66.4 \\
Tensile mod. elast. [GPa] & 3.3 & 3.2 & 3.0 \\
Flexural strength [MPa] & 112 & 104 & 101 \\
Flex. mod. elast. [GPa] & 3.6 & 3.2 & 3.2 \\
Charpy impact strength $\left[\mathrm{kJ} / \mathrm{m}^{2}\right]$ & 23.0 & 23.2 & 22.0 \\
unnotched) & 1.24 & 1.24 & 1.24 \\
Density [g/cm $\left.{ }^{3}\right]$ & 54 & 55 & 55 \\
HDT B $(0.45 \mathrm{MPa})\left[{ }^{\circ} \mathrm{C}\right]$ & 24 & 22 & 14 \\
MFR [g/10perc] $210^{\circ} \mathrm{C}, 2.16 \mathrm{~kg}$ & $55-60$ & $55-60$ & $55-60$ \\
$T_{g}\left[{ }^{\circ} \mathrm{C}\right]$ &
\end{tabular}


pressure was 600 bar, holding time was $20 \mathrm{~s}$, while residual cooling time was $40 \mathrm{~s}$. The injection molded specimens were subjected to mechanical, thermal dimensional stability, differential scanning calorimetry tests and scanning electron microscopy examination. We also examined the effect of crystalline structure and NR content in the case of the 3100HP PLA at heat treatment temperatures of $80,100,120$ and $140{ }^{\circ} \mathrm{C}$. Heat treatment lasted 1 hour in a TYFSF WGL 45B heat chamber.

Differential Scanning Calorimetry measurements were performed on a TA Instruments Q2000 calorimeter (NewCastle, USA). 3-6 mg samples were taken from the middle of the cross-section of the injection molded specimens. Firstly, we took samples from unannealed injection molded specimens and performed isothermal measurements to determine necessary annealing times. Secondly, after annealing the injection molded specimens for various times or at various temperatures, we investigated the samples in non-isothermal mode (heat/cool/heat) from 0 to $200{ }^{\circ} \mathrm{C}$ at a heating/cooling rate of $5^{\circ} \mathrm{C} / \mathrm{min}$ to the determine glass transition temperature $\left(T_{g}\right)$, cold crystallization temperature $\left(T_{c c}\right)$, enthalpy of cold-crystallization $\left(\Delta H_{c c}\right)$, melting temperature $\left(T_{m}\right)$, and the enthalpy of fusion $\left(\Delta H_{m}\right)$. Crystallinity was calculated from the first heating scan of the injection molded specimens with Eq. (1):

$$
X_{c}=\frac{\Delta H_{m}-\Delta H \Delta_{c c}}{\Delta H_{f} \Delta(1-a)} \cdot 100 \% .
$$

where $X_{c}(\%)$ is the calculated crystallinity, $\Delta H_{m}(\mathrm{~J} / \mathrm{g})$ and $\Delta H_{c c}(\mathrm{~J} / \mathrm{g})$ are the enthalpy of fusion and the enthalpy of cold crystallization, respectively, a [-] is the amount of NR in the blend, and $\Delta H_{f}(\mathrm{~J} / \mathrm{g})$ is the enthalpy of fusion for $100 \%$ crystalline PLA (93.1 J/g) [3].

We determined particle size using SEM images of the cryogenic fracture surfaces of the specimens. Particle size was determined with the Image $\mathrm{J}$ software.

Heat Deflection Temperature measurements were performed on a Ceast HV3 type HDT (Torino, Italy) measuring device, according to the ISO 75 standard. HDT $\mathrm{B}$ type measurements were carried out in flatwise mode with a loading stress of $0.45 \mathrm{MPa}$, heating rate of $2^{\circ} \mathrm{C} / \mathrm{min}$ $\left(120^{\circ} \mathrm{C}\right.$ /hour) and with a span length of $64 \mathrm{~mm}$.

The mechanical properties of the annealed and unannealed PLA specimens were analyzed with tensile, flexural and Charpy tests. The tensile and the flexural tests were performed on a Zwick Z020 universal testing machine (Ulm, Germany) equipped with a Zwick BZ 020/TN2S force measuring cell with a force limit of $20 \mathrm{kN}$ and with a crosshead speed of $5 \mathrm{~mm} / \mathrm{min}$. The Charpy impact tests were performed on notched samples with a Ceast Resil Impactor (Torino, Italy) impact testing machine equipped with a 2 J impact energy hammer and a DAS8000 data collector unit. All of the tests were performed at room temperature and at a relative humidity of $50 \pm 10 \%$.

Scanning electron microscopy (SEM) was performed with a Jeol JSM 6380LA type electron microscope. The fracture surfaces of the tensile specimens were examined. $\mathrm{An} \mathrm{Au} / \mathrm{Pd}$ alloy was sputtered onto the surface prior to observation, to avoid electrostatic charging.

\section{Results and discussion}

We started our tests by examining the toughness of PLA/ NR blends of different D-lactide contents which were made by extrusion. Fig. 1 shows impact strength and elongation at break as a function of D-lactide content and NR content. There is no significant difference between the three PLAs of different D-lactide contents concerning impact strength. Above $2 \mathrm{wt} \%$ NR content, notched Charpy impact strength increases. Elongation at break starts to increase above $10 \mathrm{wt} \% \mathrm{NR}$ content, which can be attributed to the fact that NR can be deformed more than PLA (Fig. 1).

The PLA samples of different D-lactide contents do not considerably differ in terms of the main strength-related properties (Fig. 2). Both strength and modulus decrease nearly linearly as NR content increases, which is expected because the strength and modulus of NR is considerably
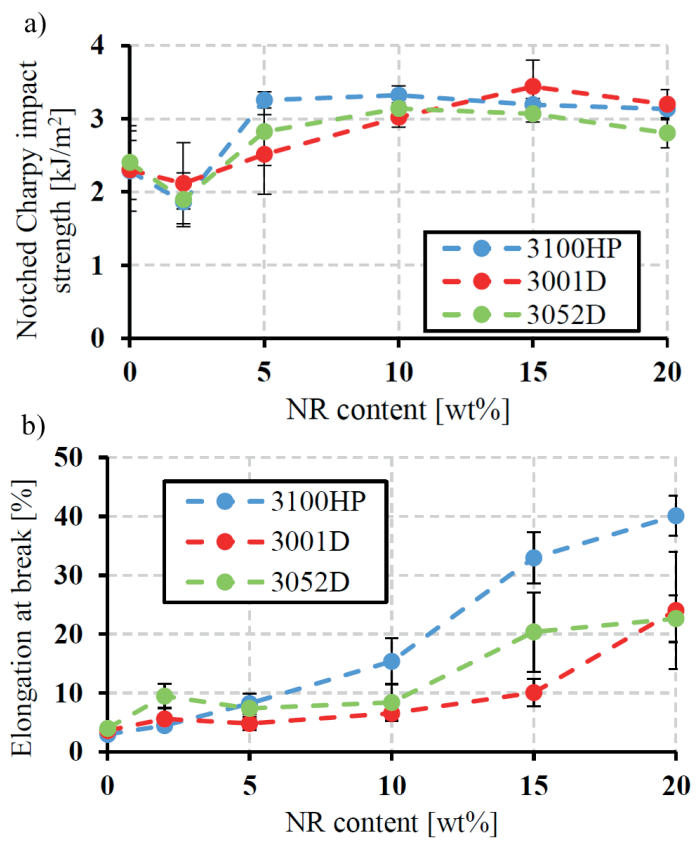

Fig. 1 Charpy impact strength a) and elongation at break b) of PLA/NR blend at different D-lactide content 


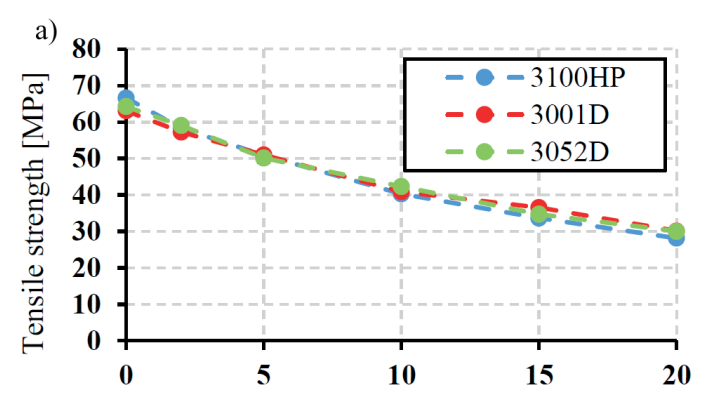

b)

NR content [wt $\%$ ]

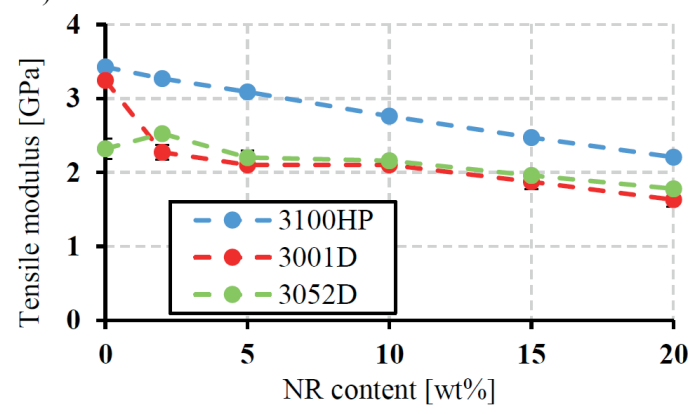

Fig. 2 Tensile strength a) and tensile modulus b) of different PLA/NR blends at different $\mathrm{D}$-lactide content

lower than those of PLA. In the case of the sample with the lowest D-lactide content, modulus was higher, which can be attributed to higher crystallinity.

The results show that D-lactide content does not significantly impact the main mechanical properties of PLA, but in blends, NR acts as a nucleating agent, as a result of which, the fraction of crystallinity increased in the case of all three D-lactide contents (Fig. 3).

The PLA with the lowest D-lactide content produced the highest values, where crystallinity grew from $21 \%$ to $35 \%$, when $5 \mathrm{wt} \%$ NR was added. Also, crystallinity only decreases a little above NR contents of $5 \mathrm{wt} \%$, which can be attributed to the nucleating effect of larger NR particles; the fraction of crystallinity was higher even with $20 \mathrm{wt} \% \mathrm{NR}$ content than in the case of pure PLA samples (without NR). Due to the higher fraction of crystallinity, the 3100HP type PLA is better than the other two types of higher D-lactide content, in terms of modulus, elongation at break.

Then, we analyzed specimens injection molded from blends produced with the internal mixer and by extrusion. Based on the results of PLA types and blends, we chose the $3100 \mathrm{HP}$ type PLA because it had the lowest D-lactide content, because the highest crystalline fraction can be achieved with this type of PLA. First, we examined the particle size distribution of the NR phase in the PLA/NR blends produced by extrusion and internal mixing (Fig. 4-5). The particle size distributions show that as NR content increases, average particle size also increases

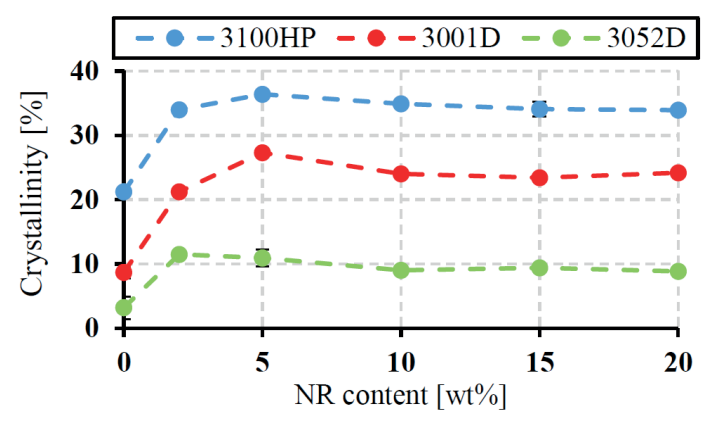

Fig. 3 Crystallinity of different PLA/NR blends at different D-lactide content

a)

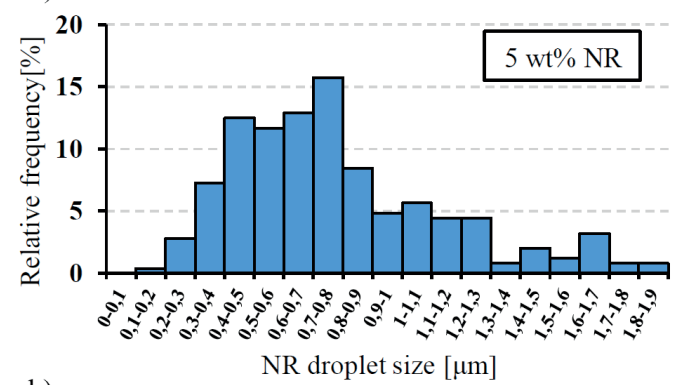

b)

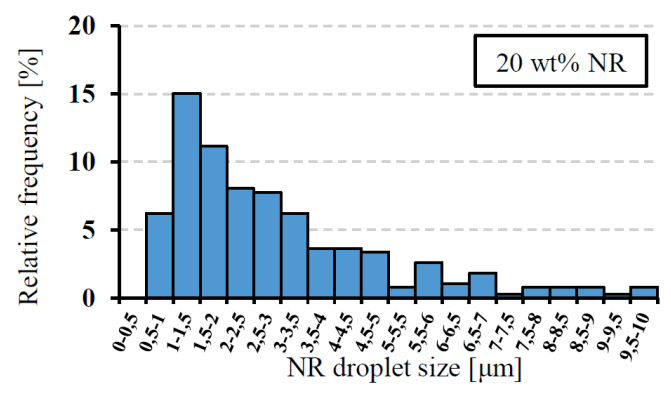

Fig. 4 Particle size distribution PLA/NR blends made with twin srew extrusion at $5 \mathrm{wt} \%$ a) and $20 \mathrm{wt} \%$ b)

and the internal mixer produced smaller particles at the same NR content than extrusion. At $5 \mathrm{wt} \% \mathrm{NR}$ content, the twin screw extrusion produced a sub-micron average particle, while in the case of $20 \mathrm{wt} \% \mathrm{NR}$, the diameter of most particles was between 1-7 $\mu \mathrm{m}$.

After particle size analysis, we examined the crystallinity and crystalline structure of annealed and unannealed PLA/NR blends. As the results show, the manufacturing technology has little effect on the crystallinity of unannealed samples (Fig. 6).

The difference in crystallinity can be attributed to the more pronounced nucleating effect of the smaller NR particles produced with the internal mixer. The nucleating effect of NR can also be seen, which resulted in the considerably higher crystallinity of PLA. The nucleating effect decreases in the case of high NR contents because NR 
a)

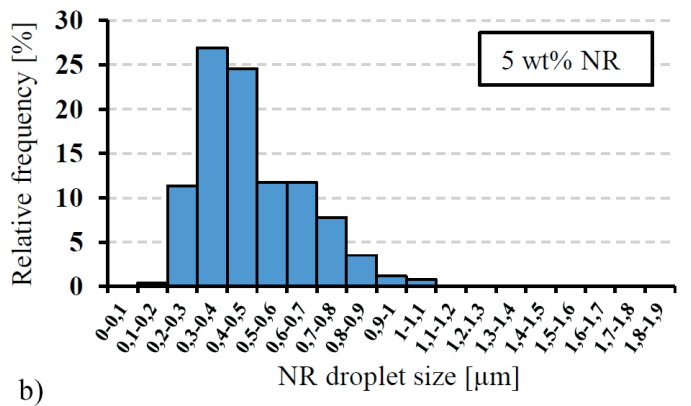

b)

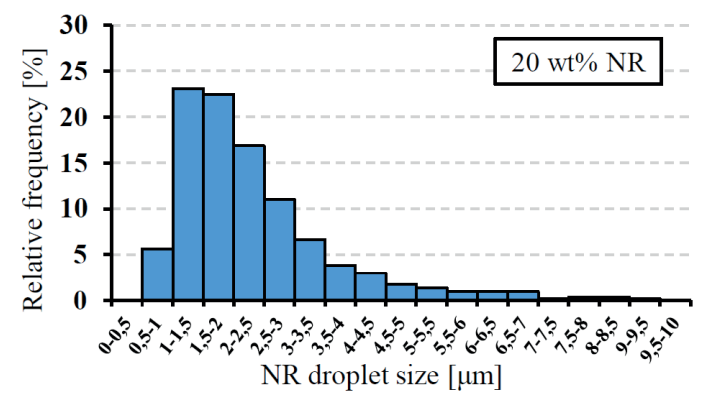

Fig. 5 Particle size distribution PLA/NR blends made with internal mixing at $5 \mathrm{wt} \%$ a) and $20 \mathrm{wt} \%$ b)

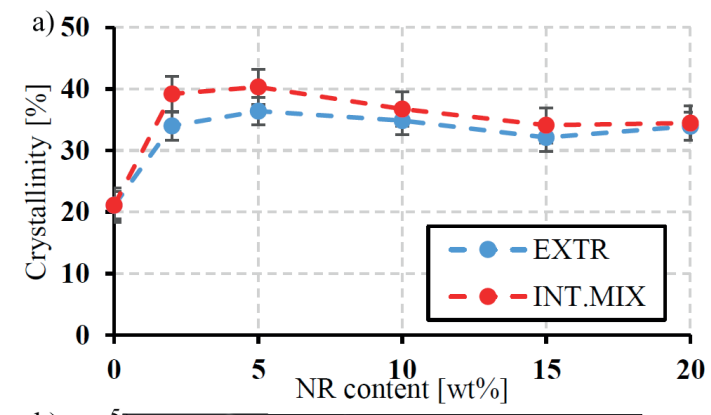

b)

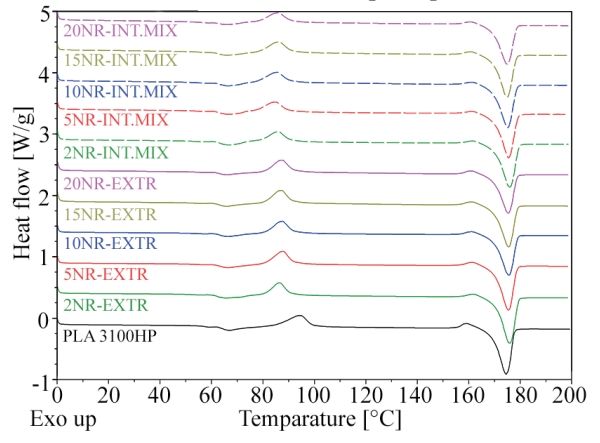

Fig. 6 Crystallinity a) and DSC first heating scans b) of PLA/NR blends produced by different techniques

contents over $10 \mathrm{wt} \%$ result in larger NR particles, whose nucleating effect is worse. The DSC curves also show an exothermic cold crystallization peak in the $80-100{ }^{\circ} \mathrm{C}$ range, which suggests that injection molded unannealed samples did not reach the maximum possible fraction of crystallinity even in the case of blends produced with an internal mixer. Also, before the crystalline melting peak, a small exothermic peak can be observed, which shows the $\alpha \rightarrow \alpha$ crystallite type transformation during the test, which indicates that the samples contained the less perfect $\alpha$ ' crystallite type. It can also be seen that the crystalline melting peak of the samples produced with an internal mixer shifted a little towards higher temperatures compared to the samples made by extrusion. The cold crystallization peak shifted towards lower temperatures, which also indicates the nucleating effect of NR, as shown earlier in the analysis of D-lactide content.

Another main goal of our research is the investigation of the cross-effect of NR content and crystallinity/crystalline type. Therefore, we subjected PLA/NR samples of the lowest D-lactide content (3100HP PLA) to 1 hour of treatment at $80,100,120$ and $140{ }^{\circ} \mathrm{C}$, then we analyzed the crystallinity of the samples by DSC (Fig. 7), and performed mechanical and HDT tests, and examination by SEM.

After heat treatment, the exothermic peak indicating cold crystallization disappeared but the small exothermic peak before the crystalline melting peak, showing the $\alpha \rightarrow \alpha$ crystalline type transformation remained in the case of samples containing NR. This means that in spite of the heat treatment at a higher temperature, the more perfect $\alpha$ crystalline type did not appear in the PLA. This is related to the nucleating effect of NR, which pushes cold crystallization towards lower temperatures, therefore conditions are more favorable for the formation of the $\alpha$ ' crystallite type during heat treatment. However, as the temperature

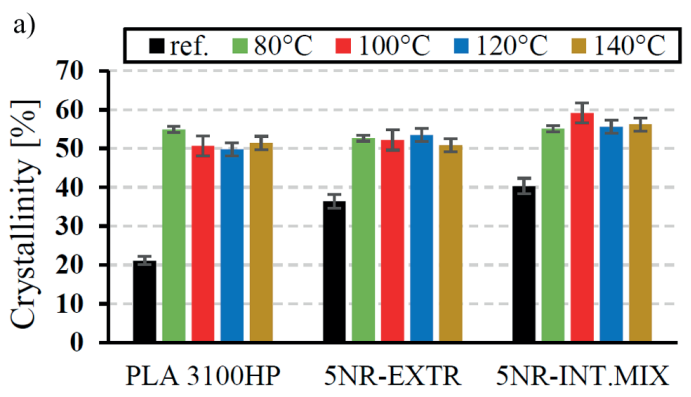

b)

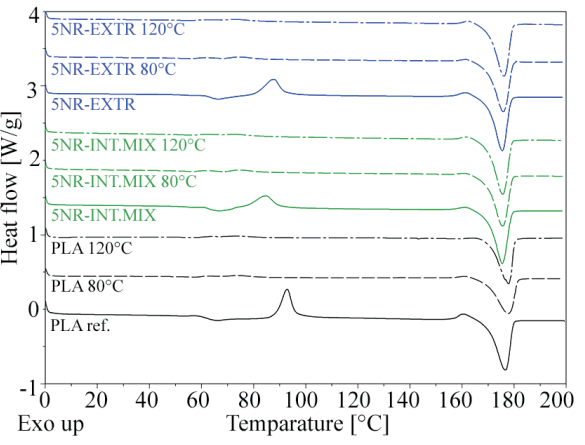

Fig. 7 Crystallinity a) and DSC first heating scans b) of annealed PLA/5NR blends produced by different techniques 
of heat treatment was increased, the peak temperature of the transformation of the $\alpha \rightarrow \alpha$ crystallite type shifted towards higher and higher temperatures, which indicates a more and more stable $\alpha$ ' crystallite type. The fraction of crystallinity also increased in the samples as a result of heat treatment and reached a maximum between 50-60\%.

The toughness of PLA/NR blends can be characterized well with notched impact strength (Fig. 8) and elongation at break (Fig. 9). In the case of unfilled $3100 \mathrm{HP}$ PLA, impact strength increased from $2 \mathrm{~kJ} / \mathrm{m}^{2}$ to $13 \mathrm{~kJ} / \mathrm{m}^{2}$ with subsequent heat treatment at $100{ }^{\circ} \mathrm{C}$. When $\mathrm{NR}$ is added, this increase of impact strength is more moderate in the case of unannealed PLA and the two different manufacturing technologies did not result in considerable differences in impact strength. However, if subsequent heat treatment and combination with NR are applied together, a positive cross-effect can be observed in the increase of the impact strength of PLA. As a result, the maximum $13 \mathrm{~kJ} / \mathrm{m}^{2}$ impact strength of pure PLA achieved by heat treatment grew to $23 \mathrm{~kJ} / \mathrm{m}^{2}$ with the addition of only $2 \mathrm{wt} \% \mathrm{NR}$, even in the case of samples made by extrusion. The cross-effect decreases when NR content is above $5 \mathrm{wt} \%$, or the temperature of heat treatment is increased above $100-120^{\circ} \mathrm{C}$, which can be attributed to the larger NR particles due to the higher NR content on the one hand, and to the more stable $\alpha$ ' crystallite type. When the internal mixer is used, this cross-effect is stronger even in the case of higher NR contents; a maximum
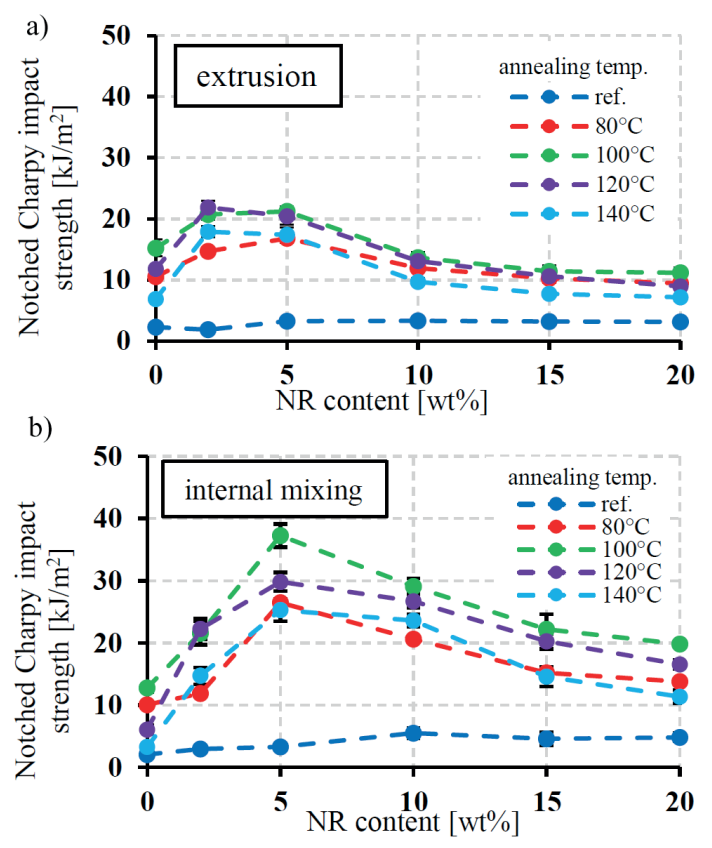

Fig. 8 Notched Charpy impact strength of annealed PLA/NR blends produced by extrusion a) and internal mixing b)
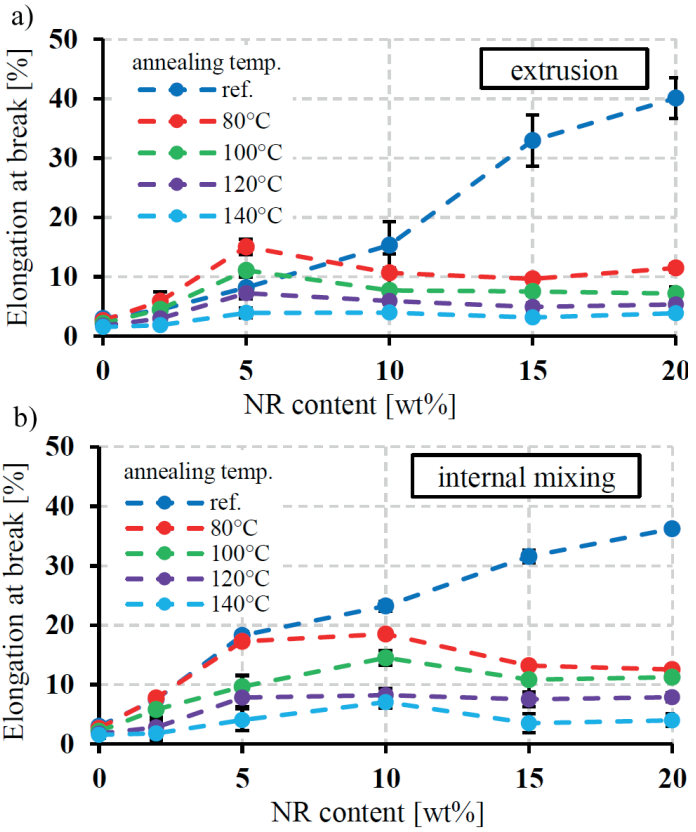

Fig. 9 Elongation at break of annealed PLA/NR blends produced by extrusion a) and internal mixing b)

impact strength of $37 \mathrm{~kJ} / \mathrm{m}^{2}$ was achieved with $5 \mathrm{wt} \% \mathrm{NR}$ content and with a heat treatment temperature of $100{ }^{\circ} \mathrm{C}$. This is because the internal produces smaller NR particles and mixer disperses them better than extrusion; SEM images can provide more information about this.

The internal mixer produces better results in the case of elongation at break as well, although to a smaller extent than in the case of impact strength. Strength and modulus decreased as NR content was increased. Blends of $5 \mathrm{wt} \%$ NR content were the best in terms of impact strength; tensile strength was $50 \mathrm{MPa}$, flexural strength was $85 \mathrm{MPa}$, while modulus values were between 3 and $3.5 \mathrm{GPa}$ at this NR content.

The SEM images (Fig. 10) show the difference between the two manufacturing technologies; by internal mixing smaller NR particles can be produced even in the case of higher NR contents. The above-mentioned cross-effect can also be observed: a tough fracture surface did not form when NR was applied only but when NR and heat treatment were applied together, a tough fracture surface can be observed.

The results show that PLA with the appropriate NR content combined with the proper heat treatment produces a blend whose impact strength is higher than that of ABS, which is generally used for its toughness. For this reason, the PLA/NR blend we produced may even be the material of engineering products where extra toughness is required. 

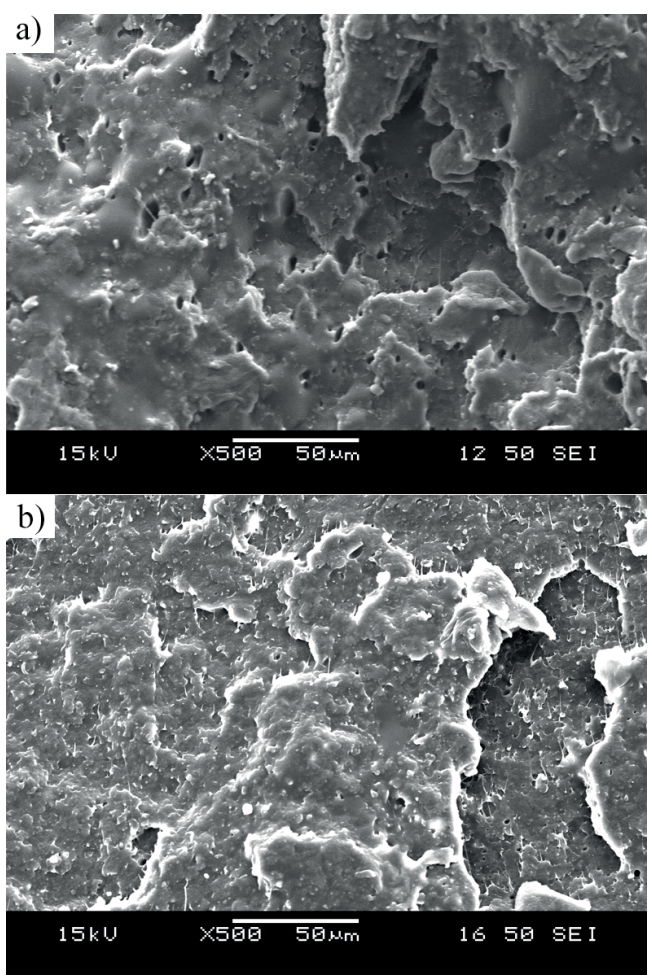

Fig. 10 SEM images of annealed PLA/5NR blends produced by extrusion a) and internal mixing $b$ )

\section{Summary}

In our work, the effect of natural rubber (NR) was investigated on various D-Lactide content Poly(Lactic Acid) with or without heat treatment (annealing). It was found that D-Lactide content had only minor effect on the properties of NR filled PLA, at the same time, in case of the lowest D-Lactide content PLA; it had slightly higher modulus and heat deflection temperature (HDT) due to increased crystallinity. When investigating the effect of processing (internal mixer and twin screw extrusion), it was found that by using internal mixer, much lower NR particle size could be reached, moreover, due to the lower particle size, it had higher nucleating ability on PLA. Accordingly, with $5 \mathrm{wt} \%$ NR content the crystalline ratio

\section{References}

[1] Garlotta, D. "A Literature Review of Poly(Lactic Acid)", Journal of Polymers and the Environment, 9(2), pp. 63-84, 2001. https://doi.org/10.1023/A:1020200822435

[2] Auras, R., Lim, L-T., Selke, S. E. M., Tsuji, H. (eds.) "Poly(Lactic Acid): Synthesis, Structures, Properties, Processing, and Applications", John Wiley \& Sons Inc., Hoboken, New Jersey, 2010. https://doi.org/10.1002/9780470649848

[3] Lim, L.-T., Auras, R., Rubino, M. "Processing technologies for poly(lactic acid)", Progress in Polymer Science, 33(8), pp. 820$852,2008$.

https://doi.org/10.1016/j.progpolymsci.2008.05.004 of up to $35 \%$ can be achieved during injection molding in the case of the PLA with the smallest D-lactide content (3100HP). This nucleating effect slightly decreases with the increase of NR content. These NR filled PLA blends were annealed at $80,100,120$ and $140{ }^{\circ} \mathrm{C}$. It was found that NR promotes the formation of the less-ordered $\alpha$ crystal forms during annealing due the fact that NR lowers the crystallization temperature of PLA to a temperature range where $\alpha$ ' crystal form preferable develops. The combined use of NR and subsequent heat treatment produces a beneficial cross-effect: the impact strength of the heattreated PLA/NR blend significantly surpasses the impact strength of the PLA/NR blend without heat treatment or that of the heat-treated unfilled PLA. Namely, when $2 \mathrm{~m} \%$ NR was added to PLA, impact strength solely increased, while when pure PLA was annealed at $100{ }^{\circ} \mathrm{C}$, its impact strength increased from $2 \mathrm{~kJ} / \mathrm{m}^{2}$ to $13 \mathrm{~kJ} / \mathrm{m}^{2}$. Finally, when both annealing was applied and NR was added to PLA, the impact strength of the annealed blend increased up to $23 \mathrm{~kJ} / \mathrm{m}^{2}$. The increase can be attributed to the presence of NR and the large amount of the $\alpha$ crystallite type formed during heat treatment due to the presence of NR. Finally, when the internal mixer is used, this cross-effect is stronger even in the case of higher NR contents; a maximum impact strength of $37 \mathrm{~kJ} / \mathrm{m}^{2}$ was achieved with $5 \mathrm{wt} \% \mathrm{NR}$ content and with a heat treatment temperature of $100{ }^{\circ} \mathrm{C}$. This is because the internal produces smaller NR particles and mixer disperses them better than extrusion.

\section{Acknowledgments}

This research was supported by The National Research, Development and Innovation Office (NVKP_16-1-20160012). The authors thank Arburg Hungária Kft. for the Arburg Allrounder 370S 700-290 injection molding machine, Lenzkes $\mathrm{GmbH}$ for the clamping tool system as well as Piovan Hungary Kft. and Tool-Temp Hungária Kft.for their support.

[4] Carrasco, F., Pagès, P., Gámez-Pérez, J., Santana, O. O., Maspoch, M. L. "Processing of poly(lactic acid): Characterization of chemical structure, thermal stability and mechanical properties", Polymer Degradation and Stability, 95(2), pp. 116-125, 2010. https://doi.org/10.1016/j.polymdegradstab.2009.11.045

[5] Fambri, L., Migliaresi, C. "Crystallization and Thermal Properties", In: Auras, R., Lim, L-T., Selke, S. E. M., Tsuji, H. (eds.) Poly(Lactic Acid): Synthesis, Structures, Properties, Processing, and Applications, John Wiley \& Sons Inc., Hoboken, New Jersey, 2010, pp. 113-124.

https://doi.org/10.1002/9780470649848.ch9 
[6] Ren, J. "PLA crystallization behavior and nucleating agents", In: Ren, J. (ed.) Biodegradable Poly(Lactic Acid): Synthesis, Modification, Processing and Applications, Springer, New York, 2010, pp. 124-129.

[7] Saeidlou, S., Huneault, M. A., Li, H., Park, C. B. "Poly(lactic acid) crystallization", Progress in Polymer Science, 37(12), pp. 1657-1677, 2012. https://doi.org/10.1016/j.progpolymsci.2012.07.005

[8] De Santis, F., Pantani, R., Titomanilio, G. "Nucleation and crystallization kinetics of poly(lactic acid)", Thermochimica Acta, 522(1-2), pp. 128-134, 2011.

https://doi.org/10.1016/j.tca.2011.05.034

[9] Miyata, T., Masuko, T. "Crystallization behavior of poly(L-lactide)", Polymer, 39(22), pp. 5515-5521, 1998.

https://doi.org/10.1016/S0032-3861(97)10203-8

[10] Zhang, J., Tashiro, K., Tsuji, H., Domb, A. J. "Disorder-to-Order Phase Transition and Multiple Melting Behavior of Poly(L-lactide) Investigated by Simultaneous Measurements of WAXD and DSC", Macromolecules, 41(4), pp. 1352-1357, 2008.

https://doi.org/10.1021/ma0706071

[11] Pan, P., Zhu, B., Kai, W., Dong, T., Inoue, Y. "Polymorphic Transition in Disordered Poly(l-lactide) Crystals Induced by Annealing at Elevated Temperatures", Macromolecules, 41(12), pp. 4296-4304, 2008.

https://doi.org/10.1021/ma800343g

[12] Pan, P., Inoue, Y. "Polymorphism and isomorphism in biodegradable polyesters", Progress in Polymer Science, 34(7), pp. 605-640, 2009.

https://doi.org/10.1016/j.progpolymsci.2009.01.003

[13] Bitinis, N., Verdejo, R., Cassagnau, P., Lopez-Manchado, M. A. "Structure and properties of polylactide/natural rubber blends", Materials Chemistry and Physics, 129(3), pp. 823-831, 2011. https://doi.org/10.1016/j.matchemphys.2011.05.016

[14] Xu, C., Yuan, D., Fu, L., Chen, Y. "Physical blend of PLA/NR with co-continuous phase structure: Preparation, rheology prperty, mechanical properties and morphology", Polymer Testing, 37, pp. 94-101, 2014.

https://doi.org/10.1016/j.polymertesting.2014.05.005

[15] Pongtanayut, K., Thongpin, C., Santawitee, O. "The Effect of Rubber on Morphology, Thermal Properties and Mechanical Properties of PLA/NR and PLA/ENR Blends", Energy Procedia, 34, pp. 888-897, 2013.

https://doi.org/10.1016/j.egypro.2013.06.826
[16] Jaratrotkamjorn, R., Khaokong C., Tanrattanakul V. "Toughness enhancement of poly(lactic acid) by melt blending with natural rubber", Journal of Applied Polymer Science, 124(6), pp. 50275036, 2012.

https://doi.org/10.1002/app.35617

[17] Buksut, B., Deeprasertkul, B. "Effect of Nucleating Agents on Physical Properties of Poly(lactic acid) and Its Blend with Natural Rubber", Journal of Polymers and the Environment, 19(1), pp. 288-296, 2011. https://doi.org/10.1007/s10924-010-0278-9

[18] Odent, J., Raquez, J-M., Leclère, P., Lauro, F., Dubois, P. "Crystallization-induced toughness of rubber-modified polylactide: combined effects of biodegradable impact modifier and effective nucleating agent", Polymers for Advanced Technologies, 26(7), pp. 814-822, 2015. https://doi.org/10.1002/pat.3513

[19] Bitinis, N., Fortunati, E., Verdejo, R., Bras, J., Kenny, J. M., Torre, L., López-Manchado, M. A. "Poly(lactic acid)/natural rubber/cellulose nanocrystal bionanocomposites. Part II: Properties evaluation", Carbohydrate Polymers, 96(2), pp. 621-627, 2013. https://doi.org/10.1016/j.carbpol.2013.03.091

[20] Chen, Y., Yuan, D., Xu, C. "Dynamically Vulcanized Biobased Polylactide/Natural Rubber Blend Material with Continuous Cross-Linked Rubber Phase", ACS Applied Material \& Interfaces, 6(6), pp. 3811-3816. 2014. https://doi.org/10.1021/am5004766

[21] Yuan, D., Xu, C., Chen, Z., Chen, Y. "Crosslinked bicontinuous biobased polylactide/natural rubber materials: Super toughness, "net-like"-structure of NR phase and excellent interfacial adhesion", Polymer Testing, 38, pp. 73-80, 2014. https://doi.org/10.1016/j.polymertesting.2014.07.004

[22] Yuan, D., Chen, K., Xu, C., Chen, Z., Chen Y. "Crosslinked bicontinuous biobased PLA/NR blends via dynamic vulcanization using different curing systems", Carbohydrate Polymers, 113, pp. 438-445, 2014. https://doi.org/10.1016/j.carbpol.2014.07.044

[23] Gergó, P. "Gumik kémiája és technológiája" (Rubber chemistry and technology), Pannon Egyetem, Veszprém, Hungary, 2012.

[24] Bartha, Z. "Gumiipari kézikönyv I. kötet" (Rubber technology handbook, Part 1.), Taurus-OMIKK, Budapest, Hungary, 1988. 